\title{
OPINIÃO
}

\section{Ilusões do desenvolvimento, ilusões da prática da docência}

\author{
Igor Zanoni Constant Carneiro Leão* \\ Denise Maria Maia**
}

Entre os muitos aspectos que distinguem a escola de primeiro e segundo graus da geração entre o final dos cinqüenta e o início dos setenta, um pouco ao acaso podemos citar um sentimento de solidariedade social criado no que Ricardo Bielchowsky chamou de "o ciclo ideológico do desenvolvimentismo" e que a ditadura militar não pode apagar ou perderia de todo sua já contestada legitimidade. Ele significava que ao menos ideologicamente todos tinham lugar à mesa da Pátria, com seus serviços úteis mesmo quando modestos como o do indispensável lixeiro. Este por sua vez tinha um salário real provavelmente muito maior que o de seus colegas atuais, o que dava maior consistência à fábula. Muitos de nós lembram que, antes da ditadura militar, prevalecia entre escola, criança e lar um ambiente como o que nós dois vivemos pessoalmente.

No banco da escola, manejando nossas canetas de pena de aço molhadas num tinteiro de vidro, sabíamos que não nos perderíamos no futuro. Estávamos na escola, e ignorávamos os que não estavam, nossos pais tinham profissões liberais ou eram operários, militares, corretores de imóveis, mas todas essas profissões garantiam o sustento da família e as expectativas quanto às crianças podiam ser vividas em um clima pacífico. É claro que existiam as "crianças da rua", os mais pobres, e nós, os ascendentes de classe média, mas a apartação social estava longe da que viria a acontecer nos anos oitenta, com sua pobreza abjeta, suas drogas, seu lixo midiático e sua miséria. Os professores também eram muito respeitados porque sabíamos da sua importância para nós, especialmente os mais pobres de nós. Mais do que isso, eram um dos nossos, nossos segundos pais, a escola era nosso segundo lar. Nós tivemos professores no primário e ginásio experientes, que tinham posições respeitáveis na cidade, escreviam livros e tinham excelente formação, ganhavam razoavelmente, como nossos pais, e dispunham de tempo para nos desasnar.

\footnotetext{
* Doutor em Economia pela Universidade Estadual de Campinas - UNICAMP. Professor do Departamento de Economia da Universidade Federal do Paraná - UFPR. Endereço eletrônico: igorzaleao@yahoo.com.br.

** Doutora em Educação pela Universidade Federal de Minas Gerais - UFMG. Professora do Departamento de Economia da Universidade Federal do Paraná - UFPR. Endereço eletrônico: denimaia@ufpr.br.
} 
Pensando nas diferenças entre o ensino fundamental e o médio cursado pelas duas últimas gerações deste século XX, é fácil elaborar uma lista compreensível e de boas razões dessas diferenças. Estas últimas se originam nas duas grandes crises do último quartel do século $\mathrm{XX}$, a crise do milagre sobreposta à do petróleo, e a crise da dívida externa que condiciona fortemente nosso estilo de crescimento e nossas opções políticas e econômicas nos anos 80 até este final de primeira década do século XXI, quando outra crise internacional veio travar a economia nacional, dada a sua estrutura, herdada das outras duas mencionadas.

Este período longo e turbulento se passa dentro de um quadro ainda marcado no Brasil por um contestado, mas sólido poder político da direita tradicional, dos grandes proprietários de terra e donos do Congresso, com enorme poder local e regional, e a direita liberal e privatizante de matriz udenista com eixo no PSDB e poder nos grandes centros urbanos de São Paulo e Minas Gerais. A opção hoje no poder, de matriz desenvolvimentista associado a um conjunto de emergentes, os chamados BRIC's, tem uma visão social e democrática mais expressiva e de maior apelo popular, sintonizando-se com a maior parte da América do Sul, mas ainda deixando de lado questões fundamentais ao futuro do país e do mundo, como a do meio ambiente, como se vê na ênfase dada ao ecologicamente anacrônico petróleo das camadas recém descobertas do pré-sal.

Por outro lado, esta instabilidade econômica com estabilidade política conservadora majoritária ocorreu no contexto de um país que viveu uma grande revolução agrária e agrícola, uma urbanização criadora de metrópoles marcadas pelo desemprego, a fome, a desigualdade social e políticas sociais incapazes de atuar sobre o novo quadro urbano de forma coerente, rápida e eficaz. A revolução tecnológica associada à crise e ao novo paradigma neoliberal dominante nos anos noventa, e ainda não totalmente exorcizado, aumentou nosso desemprego e marginalidade estruturais, e a educação, em particular, de pequena importância no campo tradicional, passa a ter uma importância nas novas metrópoles, inédita no Brasil por seus cruzamentos com saúde, desigualdade, saneamento, expectativa de vida e assim por diante, embora sem resolver por artes de um hipotético capital humano as dificuldades materiais e culturais da maioria da população brasileira, agravadas por uma mídia venal e elitista. O panorama é o de introdução do tráfico e da violência, da extremada apartação social, da impossibilidade de cumprir o espírito da constituição generosa e de caráter democrático e popular elaborada em 1988, a Constituição Cidadã. A classe média se fragmenta e inclui pessoas com dinheiro, remediadas e pobres, de onde vêm o maior contingente candidato às melhores escolas. 
Estas são em geral privadas no ensino fundamental e médio, demonstrando uma habilidade em oferecer formas de um aluno ser bem sucedido no vestibular, mas sem expressar uma visão de mundo política e socialmente generosa. As escolas públicas caíram no pântano da falta de quadros e de verbas, derivando para mau material didático, professores desmotivados e mal aceitos pelos alunos, porque estes têm consciência da precariedade da ajuda que a escola pode dar dados antes seus enormes déficits pessoais. Os pais dos alunos em geral não estão preparados nem motivados ou com paciência para suprir o que a escola não dá, em virtude mesmo de sua própria precária escolaridade e baixo grau de politização.

Nesse panorama, o ensino fundamental e médio fica desamparado do governo e dos pais, inclusive porque teria sido preciso montar uma elite de professores em diversas áreas rapidamente, num país a rigor ainda carente dessas elites mesmo nos centros maiores, se quiséssemos incluir todos os alunos, como manda a lei para o ensino fundamental e a alfabetização. Os resultados são professores que os alunos não sabem apreciar, até porque são pouco apreciados e compreendidos pelos professores. O tráfico sitia a escola, bem como a violência, o ambiente hostil da escola, quebrado apenas pela solidariedade dos grupos de amigos e/ou parceiros sexuais, ainda que muito jovens.

A escola privada oferece um mix de matérias que procuram resguardar o aluno no futuro profissional mais promissor, pensado já nos primeiros anos da vida da criança, como inglês, às vezes outras línguas, ensino e material didático padronizado pelas grandes escolas privadas, como o Positivo, e para o "wellness" da criança e do adolescente ministram-lhe aulas de dança, capoeira, judô, e assim por diante.

A concepção universitária transita ainda entre universidades de modelo clássico ou de molde corporativo e atende a demandas próprias do mercado de trabalho. Falta desenvolver algo de caráter mais multi-formativo, que atenda a um desenvolvimento social extremamente variável, mais flexível, multi, inter e transdisciplinar, mas que também capacite para novos modos de cidadania, num tempo rápido o suficiente para lidar com as voláteis transformações de nossa era. Somente agora começa a existir o espaço para o debate de novos modelos que capacitem melhor as universidades latinoamericanas para um novo século tremendamente transformado em seus processos produtivos.

Os debates acerca da reforma universitária no Brasil adquiriram, nos últimos anos, crescente espaço na agenda da sociedade e do governo, e, diversas propostas foram colocadas em pauta desde então. Nos recentes projetos apresentados pelo Ministério da Educação para o Congresso Nacional, há como objetivo principal duplicar o número de jovens entre 18 e 24 
anos matriculados em cursos superiores em três anos. Conforme consta no Plano de Desenvolvimento da Educação (PDE), lançado no dia 24 de abril de 2007, 100 mil novas bolsas serão oferecidas, por ano, no âmbito do Programa Universidade para Todos (Prouni) até 2010. Busca-se garantir, ao mesmo tempo, a democratização do acesso de minorias sociais ao ensino superior, mediante a crescente participação, por exemplo, de estudantes afrodescendentes - por meio do sistema de cotas - e dos alunos de baixa renda, beneficiados pelo Programa em instituições particulares de ensino superior. No entanto, o projeto sofreu muitas rejeições, inclusive em relação a aspectos mais demandados por diversos especialistas e entidades, como a autonomia universitária e o financiamento da expansão das universidades públicas, estaduais e federais.

O REUNI apresenta objetivos ainda mais ambiciosos, quais sejam, os de responder com saberes mais complexos os desafios da sociedade em permanente transformação. Os primeiros ensaios como projeto Universidade Nova ${ }^{1}$ são propostas com uma base históricoconceitual que remonta a mais de quatro décadas atrás. Ficou aqui latente, porque interrompida pelas duas décadas de regime militar, a histórica discussão sobre uma nova concepção de universidade que, em período próximo, também ocorria nos EUA, baseada nos princípios funcionalistas de John Dewey e que deu origem ao processo contemporâneo daquela parte norte, mas não ao sul.

Caio Prado Júnior, talvez nosso maior historiador, bem como o grande Celso Furtado, entre outros, pensaram o desenvolvimento brasileiro como uma série de rupturas que levariam uma sociedade marcada pela desigualdade e a heterogeneidade social, a pobreza, a dependência em suas várias dimensões, herança do período colonial, até uma economia

\footnotetext{
${ }^{1}$ Os seguintes princípios são norteadores das ações previstas no Projeto Universidade Nova: Ampliação do acesso - Nos próximos 10 anos a UFBA aumentará gradativamente o número de ingressos no ensino de graduação em consonância com a política do Ministério da Educação de ampliação da oferta de vagas na rede federal de educação superior. Deverá também se buscar maior eficácia nos processos de ensino de modo a aumentar a relação professor/aluno que atualmente, na UFBA, é de 1/12; Democratização do acesso Enquanto perdurarem as profundas desigualdades sociais e a baixa qualidade da educação básica pública, que se refletem na desigualdade de oportunidades educacionais para as diferentes classes sociais, deverá ser mantido o Programa de Ações Afirmativas, destacando-se entre as mesmas o sistema de cotas para egressos de escolas públicas e etnias; Adequação e atualização das estruturas de apoio às atividades-fim As estruturas físicas, organizacionais e tecnológicas serão revistas de modo a atenderem aos novos modelos acadêmicos a serem implantados; Inovação pedagógica - Serão incentivadas e apoiadas práticas pedagógicas inovadoras e mais compatíveis com as características cognitivas de indivíduos de uma Sociedade do Conhecimento de base tecnológica; Excelência Acadêmica e Responsabilidade Social - Na implementação das suas atividades de ensino, pesquisa e extensão a Universidade terá sempre presente como referenciais orientadores o compromisso com a qualidade acadêmica e a busca da superação das carências da sociedade brasileira.
} 
nacional marcada por características opostas, como a igualdade e a homogeneidade sociais, a industrialização, a democracia e a soberania, conformando uma sociedade nacional. Esta se constitui em última análise em uma sociedade formada por laços de solidariedade social criados por uma cultura comum. Essa cultura depende de um processo de criatividade que aponte para um projeto brasileiro de nação, de estruturas sociais e econômicas que nos livre de nosso arcaísmo. Embora a construção dessa cultura extrapole a escola, não pode prescindila, bem como o conjunto de políticas e ações públicas voltadas para a superação do nosso subdesenvolvimento, que se moderniza sem romper sua herança colonial de incoesão e pobreza material e simbólica. Pensamos que este é um ponto de partida para a experiência didática romper, desconstruindo, o universo simbólico brasileiro definido pelo elitismo e o privilégio de poucos e a destituição das grandes massas.

A insegurança no emprego e na renda e em especial o declínio observado na classe média levam as famílias a uma estratégia de gastos com educação extremamente motivada pela precaução com o futuro. Embora as escolas privadas vistas como de boa qualidade sejam uma opção para formação universitária, qualquer professor sabe como remuneram mal seus funcionários, dificultam seus professores para cursar níveis mais elevados de pós-graduação, e têm uma visão mercantil que as leva a uma propaganda de que elas preparam o aluno para ganhar dinheiro, uma "Escola de Negócios". O comprometimento com a sociedade se dilui, exceto se pensarem que fazer negócios resulta no melhor esforço em prol do homem comum. O ensino público ainda é o mais valorizado, mas muito concorrido, deixando muita gente de fora, nem sempre dando aos alunos uma formação de elite, à exceção das grandes universidades de São Paulo ou Rio de Janeiro. Mas a pior face dessa história é a vinculação da criança desde cedo com o ganhar, o ter, o vencer, escalar... Lembro de ter lido em um dos pedagogos da geração baby boom que vencer é a regra dos jogos e do esporte, mas não pode ser um lema da vida, que deve estar voltada antes para a solidariedade, a solução dos grandes problemas humanos e as grandes questões da vida. Keynes sonhava com um futuro tão seguro para todos que a preocupação com ganhar muito dinheiro seria supérflua e mesmo doentia, deixando tempo livre às pessoas para pensarem e viverem o que realmente importa. Mas o atual apartheid em que se vive no Brasil e na maior parte do mundo faz as pessoas quando podem - correrem à toda atrás da grana

Segue aqui um depoimento sobra nossa prática docente no Departamento de Economia da Universidade Federal do Paraná. Recebemos todos os anos quase duzentos novos alunos, em um vestibular pouco concorrido. Estes alunos muitas vezes são medianos, 
com dificuldade de compreensão de um texto, deficiência em línguas estrangeiras, em matemática, em cultura geral e outros problemas. Mas não todos. Há alunos muito interessantes, para os quais é um prazer dar aulas ou fazer juntos com eles outro tipo de trabalho. Diversos não são jovens, muitas vezes vem matar o tédio da aposentadoria, ou o tempo que sobra depois de os filhos crescerem e vão estudar, fazer a primeira ou mais uma faculdade. Às vezes vem acompanhar os filhos no mesmo curso. Mas há alunos jovens que vem fazer uma segunda faculdade, pois há grande complementaridade entre direito e economia, ou administração e economia e assim por diante. Mas o melhor para mim é que todos estes alunos vêm estudar em uma universidade pública. Embora nossa faculdade não tenha pessoal e recursos de uma grande faculdade pública em São Paulo ou Rio, possui uma equipe de professores bastante trabalhadora, apesar de suas cisões e, portanto, de sua difícil política interna. Mas nenhum professor é, como nas faculdades privadas, horista, os salários são melhores que nas últimas e se facilita de várias formas a titulação dos professores, que assim partem por longos períodos para fazer mestrado ou doutorado muitas vezes no exterior. Temos assim um bom time com boas condições de trabalho, apesar de muitas deficiências ligadas à questão social brasileira, que cai com força em cima da escola do ensino fundamental até a pós-graduação. Os alunos, entretanto, podem fazer um bom curso, o melhor do Paraná, eu creio, que usa pontuação do Enem parcialmente em seu vestibular, aderiu ao Reuni que é uma boa ideia para aumentar o número de vagas na escola pública e chegou a usar mecanismos de cotas para negros e para alunos vindos do ensino público. Isso é importante, porque embora tenha deficiências, é possível defender com boas razões o sistema de cotas para diminuir um pouco a enorme heterogeneidade que se observa no ensino superior, e transformá-lo num espelho mais fiel da sociedade que temos ou somos. Muito importante é destacar que o aluno sai dali com chance de perceber diversas formas de estudar e aprender economia, que é uma matéria tão sujeita a crivos científicos e ideológicos que a jornalista canadense Naomi Klein, buscando uma definição, optou por esta: "economia é o que os economistas fazem". Há pessoas que se voltam mais para a política macroeconômica, outros preferem estudar a vida das empresas, ou a metodologia econômica, ou o pensamento marxista ou institucionalista, e assim por diante, o que torna a faculdade bastante atraente, pelo mais que os rígidos "escolões" que em geral são as faculdades privadas. Não há na UFPR a ideia de que a escola deve preparar para o mercado de trabalho tout court, mas para a vida e a cidadania. As cisões são penosas, mas o fato de termos um ambiente sem patrões, exceto o Ministério da Educação, cria um bom espaço para divergências, convergências e discussões 
sobre consensos mínimos. O maior problema que eu vejo é muitos alunos se destacarem no curso para, diante do precário mercado de trabalho brasileiro, tornar-se caixa no BB, embora muitos sigam boas carreiras universitárias ou se destaquem em boas empresas. O professor Adilson Antonio Volpi está preparando um projeto de empreendedorismo dentro do núcleo que estuda a vida de empresas, dirigido pelo professor Armando João Dalla Costa, que procura fazer com que os alunos enxerguem outras opções no mercado para uma vida profissional gratificante. Esta iniciativa pode ser seguida por muitas outras, como a que também existe no nosso departamento, de estudar e participar do chamado Terceiro Setor. Muitos alunos montam cooperativas interessantes e democráticas por princípio, ou projetos para populações pobres na Incubadora de Projetos da UFPR voltada para a economia solidária, ou ainda projetos semelhantes para populações pobres afetadas pelas transformações no ambiente marinho ou florestal. Enfim, isso tudo me parece mais promissor que as opções das escolas de negócios, pretendendo formar alunos diretamente para as necessidades de grandes empresas. É melhor formar bons alunos com uma sólida formação geral. Ainda estamos longe disto, mas o objetivo é este, pois um aluno assim determina melhor sua vida e não se torna objeto das políticas internas das grandes empresas. É difícil ser estudante, o período da profissionalização assusta a muitos, mas penso que a política universitária pode ajudar os jovens a descobrir um grau de liberdade mais adequado a nossa sociedade e aos interesses dos alunos, que em grande parte são criados pela visão que a escola passa. 
